Portland State University

PDXScholar

\title{
A Beginning Investigation into the Language Development of the Deaf Child Compared to that of the Hearing Child: Some Problems and Solutions in Data Collection
}

Sallie Ann Frye

Portland State University

Follow this and additional works at: https://pdxscholar.library.pdx.edu/open_access_etds

Part of the Speech Pathology and Audiology Commons Let us know how access to this document benefits you.

\section{Recommended Citation}

Frye, Sallie Ann, "A Beginning Investigation into the Language Development of the Deaf Child Compared to that of the Hearing Child: Some Problems and Solutions in Data Collection" (1974). Dissertations and Theses. Paper 1268.

https://doi.org/10.15760/etd.1267

This Thesis is brought to you for free and open access. It has been accepted for inclusion in Dissertations and Theses by an authorized administrator of PDXScholar. Please contact us if we can make this document more accessible: pdxscholar@pdx.edu. 


\title{
A BEGINNING INVESTIGATION
}

INTO

THE LANGUAGE DEVELOPMENT OF THE DEAF CHILD

COMPARED TO THAT OF THE HEARING CHIID:

SOME PROBLEMS AND SOLUTIONS

IN DATA COLLLECTION

by

SALLIE ANN FRYE

A substantial paper submitted in partial fulfillment of the requirements for the degree of

\author{
MASTER OF SCIENCE IN SPEECH \\ with an emphasis in \\ AUDIOLOGY AND SPEECH PATHOLOGY
}

Portland State University

June 1974 


\section{ACKNOWLEDGMENT}

This paper is dedicated to Dr. James Maurer under whose guidance it was expanded to a major paper. Dr. Maurer's careful reading of several drafts and many invaluable suggestions are gratefully appreciated. Thanks also are due to $\mathrm{Dr}$. Robert English for whom the paper was originally written as part of Sp. 481. Without his encouragement this task would not have been undertaken. Appreciation is also expressed to those teachers of the deaf, especially Valerie Sitnich, who generously shared their time and knowledge with me. 
The substantial paper of SALLIE ANN FRYE has been approved as presented in May, 1974.

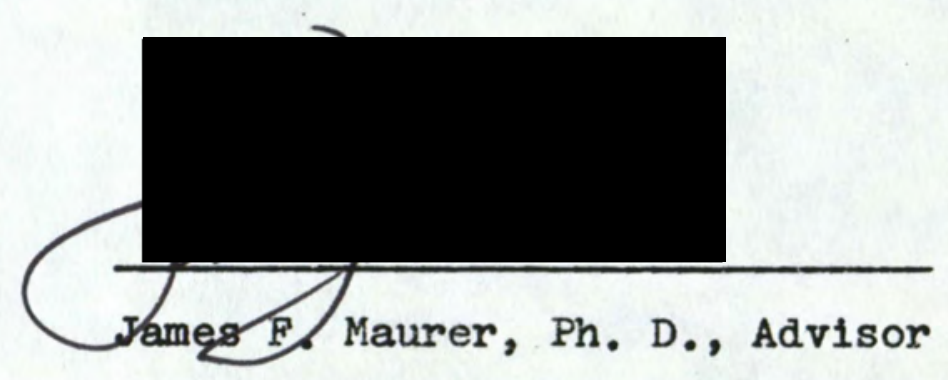


TABLE OF CONTENTS

PAGE

ACKNOWLEDGMENTS .............. CHAPTER

I INTRODUCTION ................ 1

Definitions ........... 1

Purpose ................. 3

II PRESCHOOL LANGUAGE .......... 4

III SCHOOL-AGE LANGUAGE ......... 14

Written Language ........ 14

Spoken Language ......... 21

Word Meanings and Associations .... 22

IV SUMMARY AND CONCLUSIONS ........ 24

Summary .............. 24

Conclusions ......... 25

BIBLIOGRAPHY ..................... 28 


\section{CHAPTER I}

\section{INTRODUCTION}

Normal language development depends very much upon hearing and attending to many small differences in sound. It takes almost a year for a child surrounded by talking to say his first true word. What then of the deaf child who does not have this stimulation, who is not bathed in sound? What chance does he have to develop language?

\section{DEPINITIONS}

Before moving further into this question, it is necessary to go back a step or two and define some terms. In this paper "language" is defined as the linguist Sapir (1921) defines it, "...a purely human and non-instinctive method of communicating ideas, emotions, and desires by means of a system of voluntarily produced symbols." In Sapir's view, language exists primarily in the brain, and it is a convenient view for the purpose of this paper. It is principally through speech that language is expressed, but it also may be expressed in writing and to an extent through conventional sign language. Since this paper must be limited in scope, language development, as it is expressed in speech and writing, will be the target, and such matters as faulty articulation and poor voice, important as they are, will not be 
discussed. In like manner, the whole interesting area of sign language will be excluded except in passing.

Another important word that must be defined is "deaf" . This author has followed the lead of such investigators as Brannon and Murray (1966) who place in the deaf category those with an average loss of $75 \mathrm{~dB}$ in the better ear, and whose hearIng loss was noted before the age of two and a half or three. Generally speaking, such children will not be able to learn language primarily through audition, but must rely on their remaining senses.

Having defined language and deafness, a note on why this paper is titled, "A Beginning Investigation.." is warranted. The reasons may seem contradictory. On one hand there are many books and journal articles on the deaf, too many to be Investigated within the time avallable. On the other hand, the whole subject of language development in the deaf needs more objective study. Although some good studies of the written language of the school-age deaf child have been made, not as much has been done on the spoken language of the deaf. Information on preschool language development is particularly lacking. The literature abounds in descriptions of how-to-do 1t, but factual studies of what is accomplished are few and far between.

In the course of her investigation, this author has become aware of problems in both record keeping and reporting which contribute to this paucity of data. This paper will describe these problems as well as some possible solutions. 
In addition, it will report the factual data which is avallable. Comparative data on school-age deaf and normal hearing children's written language development is definitive and clear. It is reported in Chapter III. Comparisons of preschool deaf and normal hearing children made in this paper in Chapter II are much more tenuous. They are made by looking at what data is available on the preschool deaf and then tryIng to place the child roughly in an age-level category based on what is considered to be normal language development. Barry and Eisenson (1956) and Johnson, Darley, and Spriestersbach (1963) are the reference sources. Such factors as number of words in the vocabulary and mean length of response are considered in placing the child in an approximate category of language development.

PURPOSE

This paper will attempt to present what factual material is available comparing language development in the deaf with normal language development. It will discuss problems which have become apparent in the search for this data and some solutions to the problems. Preschool language development will be taken up first, followed by a consideration of school age written and oral language, and concluding with a discussion of associations as they affect the verbal behavior of the deaf child. 
CHAPTER II

\section{PRESCHOOL LANGUAGE}

Van Riper (1963) tells us that the deaf child begins to babble at the same time as a normal child, but since he cannot hear his own sounds, loses interest, and probably has less true vocal play than the hearing child. Sykes (1940), In a study of deaf children ages three years ten months to six years ten months, indicated that deaf children vocalized spontaneously when at free play. They used sounds to get attention and indicate direction of interest. Such sounds are always accompanied by gesture; never are the sounds used alone. Personality, not the degree of hearing loss, seems to determine the amount of vocalization, according to Sykes.

Although some deaf children have no usable language at all before the age of six, when they are enrolled in schools for the deaf, others do learn language in the preschool years. The Ewings (1954) reported that some deaf children by the age of three have the ability to express some of their simple needs and thoughts in a manner that can be understood by their parents and teachers. They are described as having a variety of vocalizations from which they are able to choose words as they wish. It was also noted by these authors that some children by the age of four are ready to learn to read. Most other published information about the language of 
the preschool deaf child is random and defies categorization. Harris (1963) noted that, like the hearing child, the deaf child uses nouns and verbs first and will neglect the prepositions, conjunctions, and some pronouns. DiCarlo (1964) reported that the first word is no, the next yes. The Ewings (1954) noted that a deaf child will express an entire thought with one word (as do normals in the early stage of language development). For example, a four year old deaf child held a letter from home in his hand, waved $1 t$, and sald "ome", expressing the thought, "This is from home."

A survey of four deaf training institutions was conducted by the author in 1974 to determine the language development of the deaf child. Information was obtained through interviews, correspondence, and search of records. Several problems in data collection became apparent in the course of this investigation. First, some clinics or teachers of the deaf do not consider language development as their goal. One teacher of the deaf defined her goal as that of making the child aware of sound and helping him to use his hearing. Parental cooperation in meeting this goal is emphasized. She felt that language would develop as a result of the training of the senses, and that the same methods should be used regardless of the degree of hearing loss.

A lack of systematic record keeping is another difficulty that may explain the absence of a large body of solid information. The teacher mentioned above did keep a $\log$ of each session's activities, but made no attempt to record each word 
that the child is able to produce appropriately. Additionally, no periodic summary of progress is attempted. Since language development is not the teacher's stated goal, it is not too surprising that no specific records on it are kept. Even when periodic summaries of a child's progress are made routinely, the resulting information may not be useful to this investigation. For instance, university clinic files consulted by this author contain some information, but its value is diluted by the fact that the clinician changed each term, and there had been a considerable turnover of clinical supervisors. Each clinician had his or her own goals and records were kept accordingly. Some clinicians were interested in improving a particular aspect of sound, while others deroted their time to teaching some specific aspect of language. Overall assessment of the child's language development appears weak. Specific words or phrases that the child uttered may not have been recorded, or the record not clarify whether the responses recorded were echoic or truly meaningful.

Lack of consistency between different cliniclans' evaluations of a child's language progress is also a problem in using these university files. One child at the age of fivethree was reported to have "no structured language", but to be able to say the following words: off, on, hi, bye-bye, ball, and ow, and gross approximations to five other words. Five months later, another clinician placed this same child's expressive language at the two year level. No explanation of the basis for this marked change in evaluation was given. A 
third clinician, reporting on the boy when he was five-eleven, did not attempt any general appraisal of his language capab1lity other than to state that he usually made one word responses. She confined her remarks to his use and understanding of the concepts to, at, on, and in. Such lack of a consistent frame of reference for evaluation and record keeping purposes makes any conclusions that might be drawn from such data very tenuous.

Reports and records often suffer from vagueness. A report from an Alaskan preschool indicated, in very general terms, that the child could read and lip read very well. The teacher mentioned simple sentences which could be understood by those familiar with the child's vocabulary and sentence structure. It would appear from these reports that he was doing exceptionally well in developing language, but unfortunately, there is not enough specific data to place him at even an approximate age level in comparison to normal language development. When he was subsequently seen at a unlversity clinic, he was taught twenty-five nouns during the space of nine, one-half hour sessions. No list of the words learned was included in the report, and although the boy's language was assessed as severely retarded, no specific information was included.

Information obtained from an integrated preschool indicated that one teacher attempted to record specific words that the child produced so that his or her progress could be evaluated. She reported that one child, four and a half 
years old, said two words open, and help. Another child, also four and a half years old, was reported to be "using intelligible single words interspersed in her jargon: look, help, o.k, stop it, lay down, and sit down" (Carroll, 1974). However, on two of the four children described, the teacher could only generalize, "Some intelligible words in the middle of her rambling conversations," or "lots of single words, intelligible, and some phrases." (Carroll, 1974). In spite of the fact that this teacher expressed the belief that language development is her main goal for the children, her record keeping was not complete enough or specific enough to make a significant contribution to the study of language development.

In addition to problems in record keeping, two other factors contribute to the lack of valid comparative data in the preschool years. First, this author was unable to find any data on standardized language tests having been given to deaf preschoolers. If they are given, the results have evidently not been widely published. Second, any statements that might be made about the order in which deaf children learn to use the different parts of speech must be questioned. Deaf children learn the words that are taught to them. If they are taught all nouns, it is not very useful information to say that their language is noun language.

Extensive language data on the preschool deaf is difficult to find. However, one local group has devised a record keeping system which yields this kind of information. Infant 
Hearing Resource, as its name implies, tries to reach children at the earliest possible age. Children from infancy through four years of age are enrolled. The instructors emphasize the use of hearing aids and take an eclectic approach to language development while providing an intensive home and "school" program. The deaf and hearing impaired children are seen individually twice a week in their home and once a week at the project. Thus a child who is enrolled in the program is seen many times over a period of one, two, or more years. The records of the Infant Hearing Resource deal principally with expressive language. Sitnich, co-founder of Infant Hearing Resource, feels that it is difficult to assess the child's receptive language because situational cues, rather than the spoken word itself, may guide the child to make an appropriate response. In determining expressive language skills, she relies on her own judgment of what she herself hears, and on the judgment of the mother, if she considers the mother a reliable reporter.

The record keeping method devised by the founders of the Infant Hearing Resource provides space for the word to be written, followed by columns with headings listed below. Dates are recorded under the appropriate heading.

\begin{tabular}{l|l|l|l|l|l}
\hline $\begin{array}{l}\text { word or } \\
\text { phrase }\end{array}$ & $\begin{array}{l}\text { sign } \\
\text { only }\end{array}$ & $\begin{array}{l}\text { sign- } \\
\text { vocal }\end{array}$ & $\begin{array}{c}\text { sign and } \\
\text { word }\end{array}$ & imitation & $\begin{array}{l}\text { word } \\
\text { only }\end{array}$ \\
\hline
\end{tabular}

All of the children included in the following case histories have prelingual losses in the speech frequencies of 
$80 \mathrm{~dB}$ or more in the better ear. Great variation in language attainment is apparent. One generalization, however, was made by Sitnich (1974). No child has ever spontaneously described an event that took place earlier or in another place. Sitnich, like other teachers of the deaf, has found that what language the preschool deaf child has seems to be related to the here and now.

B. came to Infant Hearing Resource at the age of two years, ten months. At that time, he had not spoken words and seemed to understand only three words. At the end of a year's erratic attendance, B. had the following words expressively: go, allgone, open, wear, hat, cold, stop, up, down, high, bye-bye, quack-quack (for duck), ba-ba (for sheep), and Paul.

Another child, K., was first seen at twenty-one months. Even before aids were placed, he was using Jargon, although he had no real words. At the age of three, he was using some connected speech such as: come on, get your coat, bye, see you later. His inflection and intonation were reported to be excellent. This child exhibited many behavior problems between two and three, and refused to imitate, so very little progress was apparent until about three years of age when his language seemed to blossom. Sitnich has found, as have others, that behavior problems are very common with the "terrible twos", and the only thing a teacher can do is to be of stout heart and continue to "feed the language in and hope it pays off." (Sitnich, 1974). In K's case, persistance paid off, and at the age of three, he used fortyseven words and phrases spontaneously. At the time of this writing, he was spending his days at a baby-sitter's home with hearing children and plans had been made for him to attend a preschool with hearing children.

At this writing twin boys, $S_{\text {, and }} \mathrm{J}_{.}$, at the age of two and a half were not using any expressive language. They received hearing aids and started the program at two. They understand several things with gesture and one waved byebye, but as yet they had not learned to use 
their hearing for propositional language. Perhaps the fact that they are twins has complicated their language development as it sometimes does with normals.

Mrs. Sitnich is beginning to believe that pre-disposition to language in the form of spontaneous vocalization without training may be an important forecaster of eventual success in obtaining spoken language. The child who is naturally nolsy may be the one who will become "oral". (This hypothesis is worthy of further study. A longitudinal investigation that would qualify and quantify it would make an important contribution to the decision-making process that should go on concerning each deaf child's education. Parents and teachers need every bit of predictive information they can get, so that they can make wise decisions, as to the best path to language for each child.)

A younger child, T., was first seen at twelve months of age. At that time, he made three different sounds, but had no expressive or receptive language. He was two years old at the time of this writing and the development of prelanguage skills was in progress. He was aware of about twenty different sounds to the point of looking up when they were presented. He had one word in his vocabulary, no, and imitated three words or phrases, get down, more, and off. He understood some other situational cues.

Another child, D., had five oral words in her receptive language, Dande, (proper name), off, open, up, and bye-bye. These are the words she had acquired from the age of eighteen months to thirtyseven months while being seen one hundred fortythree times. She said four words consistently and appropriately, off, open, up, and an approximation of bye-bye. Since her progress in acquiring language from audition, or a combination of lip reading and audition had been so slow, her mother had added sign language to the lessons. Potential for communication with $\mathrm{D}$. had radically improved, in 
her mother's opinion, with this addition.

The final case to be reported on here is $\mathrm{Ky}$. In contrast to $\mathrm{D}$. above, Ky. learned very quickly. She had a progressive hearing loss that was measured at $65 \mathrm{~dB}$ in the better ear in 1971 and at $98 \mathrm{~dB}$ in 1973. She was seen one hundred eighteen times over a two year period. At the age of two, she understood a few words and said three words. She was then fitted with hearing aids. At the time of this writing, at age four, she was able to understand and say many words too numerous to report here individually, but which could be placed in the following categories: common social expressions, pronouns, names, verbs, body parts, clothes, food, things in nature, and transportation. As expected, Ky. understood more words than she used spontaneously. Additionally, she was reported to be using more and more two word phrases. Ky.'s progress was considered highly encouraging.

It appears that the deaf child who had made the most progress and attained the highest language level of those enrolled in the Infant Hearing Resource program was functioning at approximately the two year old level when she was four years old. At the less successful end of the scale, a child at three was seen as functioning at approximately the year old level after eighteen months of intensive work.

The Infant Hearing Resource has been in operation approximately three years, and although the number of children served is too small to draw any general methodological conclusions, its record keeping system has much to offer the investigator. Its usefulness might be enhanced by the addition of a column describing the circumstances in which the response was made and the persons present. Nevertheless, if such a record keeping system were to be in common use, definitive statements could be made about language development of the 
preschool deaf.

Knowing just what words the child has in his vocabulary has clinical significance. Furthermore, an objective record should enable parents and teachers to make intelligent decisions about methods of language development for the individual child. As the case histories from the Infant Hearing Resource demonstrate, duration of training is not necessarily related to precocious language; good record keeping is an essential basis for good decision making. Finally, good records of the preschool years, used in connection with followup studies as the children mature, could have enormous significance in evaluating different methods of teaching.

Another systematic language approach is the Monterey Language Program. This program has been used in connection with cued speech and with Seeing Essential English (signed English) in teaching language to deaf children.

\footnotetext{
"It carries built-in documentation on the progress of each child, it provides the teacher with a clearly defined methodology and a specific program to follow, and it is based on what appear to be very sound linguistic principles."

U.S. Department of Health, Education, and Welfare, 1972.
}

Perhaps the existence of such a program is an indication that the future will bring with it a greatly increased interest in the documentation of language development in the deaf child. 
CHAPTER III

\section{SCHOOL-AGE LANGUAGE}

\section{Written Language}

The oldest study constantly referred to in the literature was done by Heider and Heider in 1940. It dealt with the written language of the school-age deaf compared to that of normal hearing children. The material for the study consisted of 1,118 compositions, accounts of a short motion picture. The hearing children were eight to fourteen years of age inclusive, the deaf were eleven to seventeen inclusive. For both groups these ages were the youngest able to take the test. The children were divided into seven groups each of hearing and deaf students and the researchers concerned themselves with the comparative development of the two groups.

In regard to sentence length, hearing children use longer sentences than do the deaf, and their compositions are longer; that is, they use more sentences.

In regard to types of sentences, several observations were made. To quote Heider and Heider (1940):

1. Simple and compound sentences make up the largest proportion for both deaf and hearing.

2. The deaf use more simple than compound sentences at all age levels, while the hearing of the four highest age groups used more compound than simple sentences. 
3. Simple sentences decrease and other kinds increase with age for both deaf and hearing children.

4. The deaf use relatively more simple, fewer compound, complex and compound-complex than the hearing at all age levels. (p. 54)

Two statements that provide interesting landmarks are:

"Ten year old hearing children use as large a proportion of compound sentences as seventeen year old deaf children."

"The oldest deaf children on the average use about the same number of clauses per sentence as the eight year old hearing children."

Heider and Heider, 1940 , p. 58 .

The researchers comment that in regard to the unity of the paragraphs, those of the deaf seemed to be built up by juxtaposition, while those of the hearing showed more overlapping. The sentences of the deaf subjects included more fixed expressions that could be learned and used as units and contained less variety of expression.

The use of function words in deaf and normal hearing children was investigated by MacGinities in 1964. This study showed that deaf children could use function words if required to do so. The test involved sentence completion and indicated that at least for the thirty deaf children involved, all from the Lexington School for the Deaf, there were no striking differences between hearing and deaf children in regard to the use of function words. However, the sentences were taken from a second grade reader, and the deaf children had a mean age of twelve years five months, while the hearing 
children had a mean age of nine years seven months. This study shows that older deaf children can use function words properly, but it does not show they do so spontaneously in their writing.

In 1964 Myklebust reported on a study similar in scope to the one undertaken by the Heiders (1940). He developed The Picture Story Language Test as a basis for comparing the written language of deaf and hearing school age children. Three types of scores were derived: Productivity, Syntax, and Abstract-concrete scale. The children were tested in groups of ten. The age range tested was from seven to seventeen years, divided for purposes of comparison into two year age groups. Approximately seven hundred deaf children and an approximately equivalent number of normal hearing children participated.

The measures of language productivity were: Total Words, Total Sentences, and Words Per Sentence. Except at age seven when both groups were just learning to write, the hearing group greatly exceeded the deaf group in Total Words. Additionally, statistical analysis revealed that growth in Total Words after thirteen years of age was very slight and gradual for the deaf. Myklebust summarized by stating that the deaf child writes less than half the total number of words the hearing child writes. By this measure, the deaf child of seventeen is comparable to that of a hearing child approximately ten years of age. No consistent trend of superior performance was shown when day and residential school children 
were compared. Sex differences in favor of the female, however, appear in both hearing and deaf children.

An interesting pattern appears in studying the second measure of Productivity, Total Sentences. Although the deaf wrote fewer sentences at the earlier ages than did the hearing, by the age of fifteen their productivity was equal to the hearing. Their sentences were, however, shorter and simpler. The hearing children plateaued at about nine years of age on this measure. The deaf showed little growth until nine years of age, significant progress between nine and thirteen years, but no growth thereafter.

The last measure of Productivity, Words per Sentence, once again revealed the deficiencies of the deaf. Although both deaf and hearing groups showed a consistent, gradual increase in the number of words per sentence, the rate of growth for the deaf was much slower. Finally, at the age of seventeen, the deaf child's production was equivalent to the average eleven year old's. Myklebust noted, however, that no plateau was reached by the deaf and further language instruction after seventeen should be productive. No differences between the sexes or between the residential and day-school groups were found.

A Syntax score, or language correctness score, was derived by Myklebust for each child including such factors as carrier phrases, omissions, substitutions, additions, word order, and punctuation. Hearing children reached a plateau or maturity on these measures about the age of eleven. Deaf 
children showed their greatest deficiencies in this category. The deaf child at seventeen was approximately equal to the average child of seven in the use of syntax. Once again there were no significant differences between day and residential schools. Sex differences in learning curves were apparent, however. Deaf females were superior to the males at all age levels except at nine years.

Myklebust randomly selected the compositions of two hundred deaf children and matched them with those of hearing children of the same age, sex, and intelligence for a special analysis of the parts of speech used. Because there was extreme variability in these measures in the written compositions of the deaf, a median rather than a mean was used. Myklebust found that the hearing impaired used many more nouns than did the average child. No hearing child used all nouns after seven years of age, but some deaf children had one hundred percent noun scores through eleven years of age, and even at the thirteen and fifteen year age levels some had ninety percent scores. This heavy dependence on nouns is an indication of concreteness of language.

The use of verbs was complementary to that of nouns. Since the deaf used many more nouns, they used fewer verbs. In fact some zero scores appeared at all levels for the deaf, while they disappeared entirely after nine in the compositions of the normal hearing children.

Since the deaf child used more nouns than the hearing, he also used more articles. Additionally, Myklebust speculated 
that since articles are one, two, and three letter words, they may be less difficult and hence used often by the deaf Myklebust found the deaf used practically no pronouns before the age of nine. They made rapid progress between the age of nine and thirteen, but no further growth after the age of thirteen. They never attained the level of function of the hearing; indeed, some children at the age of fifteen wrote stories with no pronouns.

According to Myklebust, in the hearing population, use of adjectives, adverbs, and prepositions show developmental growth after the age of seven. Only in the use of prepositions does the deaf child overcome the marked deficiency present at the age of seven and become equal to the hearing at age fifteen. The same is not true of either adjectives or adverbs. The deaf use very few adjectives until the age of nine. A number of deaf children use no adjectives even at fifteen. In fact more deaf children use no adjectives at fifteen than do hearing children at nine.

Myklebust reported that the adverb is the most difficult part of speech for the deaf. They used no adverbs until the age of eleven and then usage was extremely limited. The abstract quality of this part of speech may be the cause of this extreme difficulty. The use of adverbs by the hearing is more closely related to chronological age than is the use of any other part of speech. It seems that both for the deaf and the hearing adverbs are special. For the deaf they are a special trouble. 
Conjunctions do not appear in the written language of the deaf until the age of eleven, and then not as frequently as they are used by the hearing. Some deaf children never use them at all, if Myklebust's data can be generalized to deaf children around the country.

In examining the data from the two large studies done by the Heiders (1940) and by Myklebust (1964), a consistent picture appears of the written language of the deaf. Myklebust looked at the compositions of deaf children from the age of seven, while the Helders did not consider deaf children capable of taking the test until they were eleven. Whether the deaf children of the sixties are advanced in language development in comparison to the children of the late thirties is not clear. Myklebust's mention of all noun compositions, and his finding that the syntax level of the seventeen year old deaf child is comparable to that of the seven year old hearing child, do not allow us to come to the conclusion that significant advancements in language acquisition have occurred.

Recently, a book entitled Vocabulary Norms for Deaf Children (1972) has been published. It is a listing of all the words "known" by fifty percent of the deaf children surveyed, according to age levels from eight years to seventeen years. Evidently, many schools have been contacted for information leading to these norms. This book should be of interest to anyone who wants to know about the reading vocabulary of the school age deaf. 
Spoken Language

In 1966 Brannon and Murray reported on a study they had done on the spoken syntax of deaf, hard-of-hearing and normal children. The normal hearing children ranged in age from 12 to 13.5 years with a mean age of 12.6 , while the hearing impalred were 8.7 to 18.5 years with a mean of 12.6 . By showIng fourteen color pictures to the subjects and asking them to respond with three or four sentences after each picture presentation, it was possible to come to some conclusions about the effect of hearing loss on langua ge attainment. Sentence length is considered a good barometer of language, and the sentences of the deaf were two words shorter than those of the normal hearing. The deaf had significantly more errors in syntax than the hard-of-hearing and the hard-of-hearing had more errors than the normal. Most of the sentences spoken by the hearing-impaired were simple declarative sentences; words used to expand sentences, such as auxillaries, seemed to be poorly controlled.

A later report by Brannon (1968) added more information to the comparison of the spoken language of the deaf and that of the normal hearing. Once again fourteen colored pictures were used and fifty spoken sentences were elicited from children the same ages as in the above study. From this investigation it was clear that the vocabularies of the deaf were significantly smaller than those of normal hearing children. Total numbers of words were: normal, 11,400; deaf, 4,885. The total number of different words, excluding unclassified 
and unintelligible words were: normal, 828; deaf, 298.

Except for conjunctions, the deaf children had trouble with all categories of words, but their greatest difficulties were with adverbs, pronouns, and auxillaries. Brannon (1966) characterized the deaf language as telegraphic in style and deficient in abstract concepts. Particularly noted was the difficulty with the concept of time, which is deeply involved in the use of adverbs.

\section{Word Meanings and Associations}

The preceding studies are those which are referred to over and over in the books on deafness investigated by this author. Some more recent studies published in monograph form give information on the deaf child's use and understanding of assoclations and meanings. These reports do bear out the assumption that how a deaf child is taught makes a difference in his language development. Children from two different schools for the deaf, both oral, were tested and compared to each other and to hearing students. Restaino (1969) found that the subjects from the school for the deaf in which a great deal of attention is paid to word classes gave more same-class responses (e.g. noun-noun) to the stimulus word than did either the other deaf group or the hearing group. Silverman and Rosenstein (1969) reported that deaf children use more association words in their definitions than do hearing children of the same age. They also give fewer adequate definitions. Since schools for the deaf depend heavily 
on the association technique in teaching, it is not surprising that associations would be commonly used in defining words. The number of inadequate definitions would indicate that the deaf child is not always precise about the relationship of the associate to the word to be defined.

McGettigan and Rosenstein (1969) investigated the influence of associative strength upon the ability to distinguish synonym from non-synonymous associates. Once again, schools from the two schools for the deaf were used, and it was evident that the students of one school for the deaf were super1or in performance to the other group of deaf children. The two groups of deaf students were less able than a hearing control group to identify associations correctly, and the second group of deaf children gave evidence that they confused definitions with associative relationships. Since the schools were only identified as number one and number two, it is impossible to draw any conclusions about possibly differing methods of instruction in the two institutions.

Hart (1969), a teacher of the dear, commenting on the information gained from the studies just described, calls attention to the great individual differences in language attainments of deaf children. "I am suggesting that there are certain deaf children who never master a deep understanding of language structure." (p. 58) Hart also calls for more detailed studies of the verbal achievement of the deaf students without continuously comparing them to hearing children. 
CHAPTER IV

SUMMARY AND CONCLUSIONS

\section{SUMMARY}

The evidence shows that the language development of the deaf child lags behind that of the hearing child. In his preschool years he may have very little language or he may progress in a satisfactory, although still retarded, fashion, even if he is given special training.

School age deaf children write shorter, simpler sentences, and shorter compositions than do the younger hearing children to whom they are compared. They have a poorer sense of organization and unity. In syntax, which must be considered a vital concern as a measure of language attainment, the seventeen year old deaf child's performance is consistent with the seven year old level.

In the spoken language of deaf children, sentences are shorter, vocabulary smaller, and errors in syntax more numerous than in that of hearing children. Deaf children find adverbs, pronouns, and auxillaries particularly troublesome; their language is telegraphic in style and deficient in abstract concepts.

There are indications that by most measures the language of the deaf child reaches a peak, and there is lack of further growth with age. Because of heavy emphasis on association 
training in his schooling, the deaf child uses more associations in definitions than do normal hearing children. These associations may be poorly understood and may result in mistakes in definitions. Finally, significant differences in some aspects of language development can be found between the students of one school for the deaf and another, suggesting methodological differences.

\section{CONCLUSIONS}

The course of development of deaf language has yet to be definitively charted. Published data on preschool language development is fragmentary. The information this author obtained from the Infant Hearing Resource is invaluable because, as we have shown, it involves systematic documentation, obtalned over a period of time, from a very large number of contacts with an individual child. Such documentation, at least in published form, appears to be rare. Were it to be published, it might stimulate other groups around the country to start similar record keeping, or to publish results that they may have already accumulated.

Data on the written language of the school age child is fairly extensive, but still more needs to be known. School by school comparisons, now generally unavailable, and information from other English speaking countries would be helpful in determining what methods work best in teaching language. Many questions remain unanswered. Published studies of the spoken language of the deaf deal with only very limited 
numbers of students. Enormous individual differences exist in all facets of language achievement among the deaf and the reasons for these discrepancies are not clear. Are the insights of linguists being applied to teaching language to the deaf? W1th what success? Can behavior modification techniques offer significant help? Without more information, dec1sions will be made on intuition, on emotion, on hope. Even the experience of teachers may be clouded by their emotional commitment to one method or another, in the absence of some standard for measurement. Deaf children deserve better than this. 
B I B L I O G R A P H Y 
Berry, Mildred F. and Eisenson, Jon. Speech Disorders: Principles and Practices of Therapy. New York: AppletonCentury-Crofts (1956).

Brannon, John B. and Murray, Thomas, The spoken syntax of normal, hard-of-hearing and deaf children. Journal of Speech and Hearing Research, 9, 604-610 (1966).

Brannon, John B., Linguistic word classes in the spoken language of normal, hard - f hearing and deaf children. Journal of Speech and Hearing Research, 11, 279-287 (1968).

Carhart, Raymond, Development and conservation of speech. In Hailowell Davis and S. Richard Silverman (Eds.), Hearing and Deafness. 3rd. ed. New York: Holt Reinhart and Winston (1970).

Carroll, Judy, personal correspondence, March 15, 1974.

DiCarlo, Louis M. The Deaf. Englewood Cliffs, N.J.: Prentice-Hall (1964).

Ewing, Irene R. and Ewing, A.W.G. Speech and the Deaf Child. Manchester: Manchester University Press (1954).

Harris, Grace M. Language for the Preschool Deaf Child. New York: Grune and Stratton (1963).

Hart, Beatrice 0. , Comments by an educator of the deaf. In Joseph Rosenstein and Walter Macginities (Eds.), Verbal Behavior of the Deaf Child: Studies of Word Meaning and Associations. T.C. Series in Special Education. Francis P. Connor (Ed.). New York: Teacher College Press (1969).

Helder, Fritz and Heider, Grace Moore, A comparison of sentence structure of deaf and hearing children. Psychological Monographs, No. 232, 52:42-103.

Johnson, Wendell, Darley, Frederic L., and Spriestersbach, D.C. Diagnostic Methods in Speech Pathology. New York: Harper and Row (1963).

MacGinities, Walter H., Flexibility in dealing with alternative meaning of words. In Joseph Rosenstein and Walter MacGinities (Eds.), Verbal Behavior of the Deaf Child: Studies of Word Meaning and Associations. T.C. Series in Special Education. Francis P. Connor (Ed.). New York: Teacher College Press (1969). 
MacGinities, Walter, Ability of deaf children to use different word classes. Journal of Speech and Hearing Research, 4, 141-149 (1964).

McGettigan, James F. and Rosenstein, Walter, The influence of associative strength on identification of word meanings. In Joseph Rosenstein and Walter MacGinities (Eds.) Verbal Behavior of the Deaf Child: Studies of Word Meaning and Associations. T.C. Series in Special Education. Francis P. Connor (E.). New York: Teacher College Press (1969).

Myklebust, Helmer R. The Psychology of Deafness. 2nd ed. New York: Grune and Stratton (1964).

Restaino, Lillian C.R., Word associations of deaf and hearing child: studies of word meaning and associations. In Joseph Rosenstein and Walter MacGinities (Eds.), Verbal Behavior of the Deaf Child: Studies of Word Meaning and Associations. T.C. Series in Special Education. Francis P. Connor (Ed.). New York: Teacher College Press $(1969)$.

Sapir, Edward. Language. New York: Harcourt, Brace and World, Inc. (1921).

Silverman, S. Richard and Lane, H.S., Deaf children. In Halloweil Davis and S. Silverman (Eds.) Hearing and Deafness. 3rd. ed. New York: Holt, Reinhart and Winston (1970).

S1lverman, Toby $R$. and Rosenstein, Joseph, The contribution of associative processes to written meaning. In Joseph Rosenstein and Walter MacGinities (Ed.), Verbal Behavior of the Deaf Child: Studies of Word Meaning and Associations. T.C. Series in Special Education. Francis P. Connor (Ed.). New York: Teacher College Press (1969).

Silverman-Dresner, Toby and Guilfoyle, George R. Vocabulary Norms for Deaf Children. Washington, D.C.: Alexander Graham Bell Association for the Deaf (1972).

Sitnich, Valerie, interview, January 3, 1974.

Sykes, J.L., A study of the spontaneous vocalizations of young deaf children. Psychological Monographs, No. 232, 52: $104-123(1940)$.

U.S. Department of Health, Education, and Welfare. Final Report, Contract No. OCE-8-009137-4348(019) and (615). Cued Speech Parent Training and Follow-up Program. August (1972). 
Van Riper, Charles, Speech Correction: Principles and Methods. 4 th. ed. Englewood Cliffs, N.J.: Prentice-Hall, Inc. 